\title{
Locating Medieval French, or Why We Collect and Visualize the Geographic Information of Texts
}

\author{
By David Joseph Wrisley
}

This article focuses on geographic information contained in the body of medieval French texts composed over the period of the eleventh to the fifteenth century. By "geographic information" we mean textual references made to different kinds of place names at different scales within sustained prose or poetic narrative-landmarks, settlements, regions, and countries—real and imaginary. Collecting such geographic information across a large corpus of texts and analyzing it with the digital methods that have become available to scholars in recent years allow us to create new contexts in which we can reexamine a variety of questions in literary history. The scholarly context for the article is a digital project launched in 2014, Visualizing Medieval Places, ${ }^{1}$ that seeks to arrive at a "complex understanding of cultural space-time" for the large corpus of literature written in medieval French. ${ }^{2}$

The methodological approach adopted here diverges from classic studies of medieval cartography inasmuch as it is not concerned primarily with analyzing medieval notions of space or their conceptual, visual, and cartographic expression in historical maps. ${ }^{3}$ The article looks at where, when, and how often locations are mentioned in a literary-historical corpus. We proceed from the basic idea that an evocation of a geographical location within a text is not gratuitous, and is worthy of critical exploration like any other subject. Place is, after all, as much a topical consideration as it is a geographical one. Textual geographies, as they have been called by some, visually collate spatial references found in a work, but they are not simply the depiction of a text's realism. ${ }^{4}$ Instead, they are indicative of a more layered set of relationships related to geographic space: provenance, patronage, setting, even the overlap between spaces of textual production and more symbolic or imaginary realms. This article does not deal explicitly with the concept of mapping fictional narrative, that is, the spatializing of text from a theoretical, narratological perspec-

\footnotetext{
${ }^{1}$ Visualizing Medieval Places, digital project, http://medieval.place. At the time of publication of this article, the corpus was made up of spatial data from over 150 works. An updated list of the corpus is kept at the project site. All links in this article were last consulted 18 February 2017.

${ }^{2}$ David J. Bodenhamer, "The Potential of the Spatial Humanities," in The Spatial Humanities: GIS and the Future of Humanities Scholarship, ed. David J. Bodenhamer, John Corrigan, and Trevor M. Harris (Bloomington, 2010), 14-30.

${ }^{3}$ Studies of medieval mapmaking and conceptions of space from a cartographic or conceptual perspective on space include Evelyn Edson, Mapping Time and Space: How Medieval Mapmakers Viewed Their World (London, 1999); Paul Zumthor, La mesure du monde: Représentation de l'espace au Moyen Âge (Paris, 1993); Keith Lilley, ed., Mapping Medieval Geographies: Geographical Encounters in the Latin West and Beyond, 300-1600 (Cambridge, UK, 2013).

${ }^{4}$ Eric Bulson, Novels, Maps, Modernity: The Spatial Imagination, 1850-2000 (New York, 2007).

Speculum 92/S1 (October 2017). (C) 2017 by the Medieval Academy of America. All rights reserved. This work is licensed under a Creative Commons Attribution-NonCommercial 4.0 International License (CC BY-NC 4.0), which permits non-commercial reuse of the work with attribution. For commercial use, contact journalpermissions@press.uchicago.edu. DOI: $10.1086 / 694300,0038-7134 / 2017 / 92 \$ 1-0006 \$ 10.00$.
} 
tive. ${ }^{5}$ A collection of geographic information found in a database of places, otherwise known as a gazetteer, however, does not preclude such analysis by others in the future.

This article presents a case study of data derived from medieval French texts, and it argues more broadly for scholars in medieval studies to collect geographic information at small and large scales, as others in classical and modern studies have, and to use that data in order to ask new questions about our sources. Mapping is an important research method that uses geographical location as an index of the abovementioned relationships in and between texts. It is important to note that by the term "mapping" we do not mean simply the act of compiling different forms of geographical information together in a cartographic medium, ${ }^{6}$ but we refer instead to the combined intellectual effort of curating such information in structured form and its iterative, visual representation. If this larger sense of mapping as a way of categorizing, organizing, and studying information about place is to take root in medieval studies, it must be spearheaded by research centers or other communities of practice that can balance the necessary diversity of approaches with some consensus on technical standards, as has been the case for the textual digital humanities.

Visualizing the places mentioned throughout a corpus is not a mode of inquiry new to literary studies, although in the past it generally took the form of static, paper maps and was, therefore, limited in its scope. ${ }^{7}$ Resources that scholars use on a daily basis, such as atlases or sometimes critical editions, contain diagrammatic maps that display research data, and these visuals have a strong rhetorical function. Whereas certain strands of literary and cultural studies resist mapmaking that asserts an unproblematic relationship between the space of texts and geographic space, ${ }^{8}$ others have embraced the practice of mapping, understood in the larger sense of both curation and representation, as an innovative, even "ludic" or "conjectural," 10 activity of the studia humanitatis. Access to the data behind visualizations and to the variety of computational platforms in which such information can be analyzed and represented was not, until recently, granted to scholars in all disciplines. The situation has changed significantly with the democratization of digital forms of cartography, bringing geographic information systems (GIS) to a wide base of users. This has given rise to an era of what has been called by Andrew Turner and others "neogeography." 11

\footnotetext{
${ }^{5}$ Two works taking this approach are Barbara Piatti, Die Geographie der Literatur: Schauplätze, Handlungsräume, Raumphantasien (Göttingen, 2008); and Marie Laure Ryan, Kenneth Foote, and Maoz Azaryahu, eds., Narrating Space / Spatializing Narrative: Where Narrative Theory and Geography Meet (Columbus, 2016).

${ }^{6}$ Mark Monmonier, Mapping It Out: Expository Cartography for the Humanities and the Social Sciences (Chicago, 1993).

${ }^{7}$ Jörg Döring, "Zur Geschichte der Literaturkarte (1907-2008)," in Mediengeographie: TheorieAnalyse-Diskussion, ed. Jörg Döring and Tristan Thielmann (Bielefeld, 2009), 247-90.

${ }^{8}$ Andrew Frayn, “ 'Now-Well, Look at the Chart': Mapping, Maps and Literature,” in Mapping Across Academia, ed. Stanley D. Brunn and Martin Dodge (Dordrecht, 2017), 259-85.

${ }^{9}$ Bethany Nowviskie, "How to Play with Maps," in Cultural Mapping and the Digital Sphere: Place and Space, ed. Ruth Panofsky and Kathleen Kellett (Edmonton, 2015), 107-27.

${ }^{10}$ Charles B. Travis, Abstract Machine: Humanities GIS (Redlands, CA, 2015), 19-20.

${ }^{11}$ Andrew Turner, Introduction to Neogeography (n.p., 2006).
}

Speculum 92/S1 (October 2017) 
The visualizations found in the body of this article might offend traditional cartographic sensibilities since they go beyond what has typically been considered the practice of geography and they do not have the qualities of traditional maps. They include data extracted from medieval sources visualized on contemporary base maps, fashioned according to specific research questions we have about those texts. In the branch of the digital humanities most concerned with modeling and analyzing space, known alternatively as the "spatial humanities" or the "geohumanities," the digital study of place has taken a turn away from a traditional concern of cartography, namely topography, and is "increasingly conceived though a 'topological' lens: as a set of overlapping reticulations in which the nature and frequency of links among different sites matter more than the physical distances between them." ${ }^{12}$ In this respect, collecting and visualizing geographic information could be imagined either on a traditional map grid, as is the case in this study, or in more abstract ways, such as network visualizations. Medievalists will be inspired by the research of digital classicists, who have created an open infrastructure for complex digital projects that model different elements of the classical Mediterranean world. ${ }^{13}$ Such infrastructure has paved the way for innovative research with a significant spatial dimension. ${ }^{14}$ Medieval studies must focus, in our opinion, on similar infrastructure that reflects both the complexity and diversity of our field.

Geovisualization of information is sometimes explained by the need to expand a researcher's interaction with data beyond a simple "text search" to provide a visual means of "sifting meaningful patterns from such massive datasets." ${ }^{15}$ Collecting spatial data from medieval sources, as opposed to larger digitization projects, such as creating newspaper collections, is of an entirely different scale but stems from the same general research impulse. Large source bases are likely to contain "meaningful patterns," and the ability to examine them, that is, to gain a bird's-eye view with the assistance of a computer, is tantamount to having a team of readers, even many teams of readers, at one's disposal. There is an important distinction, however, between harvesting medieval data and that of digitized newspaper collections. Whereas it is possible that the digitization of materials such as newspapers could be carried out by state-funded agencies or large library consortia, and that researchers might even be alienated from the process of its creation, data in medieval studies are a very specialized kind of information, and those involved in digital projects in medieval studies will, chances are, be quite intimately involved in their creation. For that reason, we agree, following Franco Moretti, that mapping does not play a "wholly peripheral" or "decorative" role in the study of history and culture, that is, it does not simply illustrate the results of research but can rather be part and parcel of the com-

\footnotetext{
${ }^{12}$ Elton Barker, Stefan Bouzarovski, and Leif Isaken, "Introduction: Creating New Worlds out of Old Texts," in New Worlds from Old Texts: Revisiting Ancient Space and Place (Oxford, 2015), 1-30.

${ }^{13}$ Of particular mention are Pleiades, "a community-built gazetteer and graph of ancient places" (https://pleiades.stoa.org/); and the Pelagios Commons (http://commons.pelagios.org/).

${ }^{14}$ For example, the ORBIS project is a geospatial network model of the ancient world (http://orbis .stanford.edu/).

${ }^{15}$ Andrew J. Torget and Jon Christensen, "Mapping Texts: Visualizing American Historical Newspapers," Journal of Digital Humanities 1/3 (Summer 2012), http://journalofdigitalhumanities.org/1-3 /mapping-texts-project-by-andrew-torget-and-jon-christensen/. The full project can be consulted at http:// mappingtexts.org/.
}

Speculum 92/S1 (October 2017) 
plexities of the interpretative process. ${ }^{16}$ Groups of medievalists should work to design the infrastructure for their geographical information.

The Visualizing Medieval Places (VMP) project has been collecting the place names found in different genres and periods of textual production of what scholars commonly call medieval French. The spatial and temporal coverage of the project is admittedly vast. At the time of writing this article, it contains the geographic information of some one hundred and fifty texts, with over ten thousand place-name occurrences documented. It is difficult to say what percentage of all sustained narrative texts written in medieval French this represents, although our guess is that it only a small fraction of them. ${ }^{17}$

Other humanities gazetteers, by which we mean databases of historical place names and their geographic coordinates, such as the Pleiades Gazetteer for the Greco-Roman world or the al-Thurayyā Gazetteer for the Arabograph world, do not begin with a corpus of texts per se but instead with a discipline-specific canonical atlas as their starting point for associating places with texts and spatial data. The geographic information generated from the VMP project has not begun in this way. It resembles what Janelle Jansted has defined as a literary gazetteer, that is, a list of names built from a corpus of texts, names that are significant on account of their evocation in these texts. ${ }^{18}$ The VMP project bears a resemblance to the Map of Early Modern London (MoEML) project inasmuch as it is a "hybrid historical and literary project." Jansted continues,

Literary toponyms range from spaces as large as the city to places with relatively small footprints, such as a conduit. One passage in a literary text might mention an administrative unit (a ward with clear legal boundaries), a neighborhood (an area identified primarily by perceptions and/or use), a church (with a precise footprint we can know from the archeological record), a long-gone building with uncertain coordinates, a monument, and a shop. Spatial references in a text are necessarily place names, or strictly speaking, "referring strings" of characters that people have chosen to indicate spaces made meaningful by human habitation, practices, travel, and events. ${ }^{19}$

The MoEML aims to describe London as it has been evoked in a large corpus, and its spatial boundedness resembles the approach taken in many projects adapting Geographic Information System technology to social and economic history (a field known as "historical GIS"). For the sake of comparison, let us mention several other projects in medieval studies that deal with geographic information and adopt either a corpus approach or bounded-spatial approach. The Mapping Medieval Chester project provides dynamic, diachronic views of one city, Chester, from 1200-1500, focusing on archaeology, built space, and literature and their relation to Chester's po-

\footnotetext{
${ }^{16}$ Andrew Frayn, "Now-Well, Look," 7, citing Franco Moretti, Atlas of the European Novel 1800-1900 (London, 1998), 7.

${ }^{17}$ David Joseph Wrisley, "How Many Texts Were Composed in Medieval French?," Visualizing Medieval Places (blog), 2 August 2014, http://vmp.djwrisley.com/2014/08/02/how-many-texts-were -composed-in-medieval-french/.

${ }^{18}$ Janelle Jansted, “Building a Gazetteer for Early Modern London 1550-1650," in Placing Names: Enriching and Integrating Gazetteers, ed. Merrick Lex Berman, Ruth Mostern, and Humphrey Southall (Bloomington, 2016), 129-45.

${ }^{19}$ Ibid., 130-31.
}

Speculum 92/S1 (October 2017) 
sition as a historical border town. ${ }^{20}$ The Mapping Dante project, on the other hand, takes Dante Alighieri's Commedia and links mention of places with occurrences of linguistic phenomena found in the corpus as well as graphical, nonmap representations of these occurrences. ${ }^{21}$ At the Austrian Academy of Sciences, there is an ambitious project, Mapping Medieval Conflict, aiming to represent medieval political dynamics across various means of digital representation. ${ }^{22}$ This project's placement in the midst of a digital-humanities group with other researchers in text editing, prosopography, and network mapping has led to a social-research dynamic of interdisciplinary cross-pollination, especially between traditional medieval sources and innovative modes of visualization. Likewise, the Icelandic Saga Map began as a literary corpus visualization project but has expanded into a complex, multidisciplinary project concerning landscape, environmental memory, and historical climate change. ${ }^{23}$ These four projects illustrate varieties of spatial humanities research being carried out currently in medieval studies in the United States, the United Kingdom, and Europe, each with different research parameters but all attesting to the appeal of the spatial humanities' use of the place name as a common denominator for potential interdisciplinary.

The VMP project does not begin with an atlas or a map representation, nor does it limit itself to representations of one region, but is geo-graphic in scope. It draws upon a representative sample of genres and periods, but also considers zones of literary production and the circulation of texts written in mutually comprehensible written varieties of French. The project includes texts composed in England, France, Italy, and the eastern Mediterranean and will expand to include many more texts. Its data have begun to trace the contours of the known world, or more precisely, the "named world," according to medieval French. In this respect, the project responds to scholars' calls to expand the study of medieval French beyond the traditional borders of France and the constraints of national literary studies. ${ }^{24}$ Research in the spatial humanities with medieval French materials contributes in two ways to the study of medieval literature in a global context: we examine textual production from a diversity of sites, including understudied ones; and we look at the different worlds that

\footnotetext{
${ }^{20}$ Mapping Medieval Chester: Place and Identity in an English Borderland c. 1200-1500, digital project, http://www.medievalchester.ac.uk/.

${ }^{21}$ Andrea Gazzoni, Mapping Dante: A Study of Places in the Commedia, digital project, http://www. mappingdante.com/.

${ }^{22}$ Austrian Academy of Sciences, Mapping Medieval Conflict, digital project, https://oeaw.academia .edu/MappingMedievalConflict.

${ }^{23}$ Emily Lethbridge, Icelandic Saga Map, digital project, http://sagamap.hi.is/is/. See also Emily Lethbridge and Steven Hartman, "Inscribing Environmental Memory in the Icelandic Sagas and the Icelandic Saga Map,” PMLA 131/2 (2016): 381-91.

${ }^{24}$ In particular, see Geraldine Heng, "The Global Middle Ages: An Experiment in Collaborative Humanities, or Imagining the World 500-1500 C.E.," English Language Notes 47/1 (Spring/Summer 2009): 205-16; Sharon Kinoshita, "Deprovincializing the Middle Ages," in The Worlding Project: Doing Cultural Studies in the Era of Globalization, ed. Rob Wilson and Christopher Leigh Connery (Berkeley, 2007), 61-75; and Sharon Kinoshita, "Medieval Mediterranean Literature," PMLA 124/2 (2009): 600-608.
}

Speculum 92/S1 (October 2017) 
are referred to therein. The VMP project data exists as a "digital object," a prototype of a future gazetteer, that begins to make an argument about the importance of the geographical embeddedness of medieval French texts, and we believe the model is generalizable across other languages and corpora. ${ }^{25}$ Another digital project that used and enriched VMP data and enriched VMP data from ten texts of the FrancoItalian corpus illustrates how diverse those geographies can actually be. ${ }^{26}$

Another main difference between the aforementioned MoEML gazetteer and the research carried out in the VMP project is the principle of collection. The MoEML is built using a collection of rich digital editions of early modern texts in which strings referring to places have been tagged manually in TEI XML, the de facto standard for formal markup and representation of digital texts, a process that other text mapping projects have followed. ${ }^{27}$ The VMP project, by contrast, relies on a combination of manual and semiautomatic means of extraction in order to find place names in the corpus. Lacking a large open-access initiative for the publication of medieval French texts, we have adopted a pragmatic approach of collecting toponyms in the medium in which they are most easily available to us, namely from print critical editions. Corpora do exist for medieval French (such as the Base de français medieval or the Nouveau Corpus d'Amsterdam); however, they are oriented largely towards linguistic annotation, their licenses are not necessarily open, and they are relatively small, not reflecting the overall diversity of texts found in medieval French. ${ }^{28}$ Open-culture enthusiasts may be disappointed by our approach; and medievalists will also object that there are theoretical problems with it, considering that editorial principles define the kind of text available to us and that there are known cases where different manuscript witnesses and translations exhibit very different toponymy. ${ }^{29}$ Hopefully, such obstacles will be surmounted in the future; however, the labor required to create such a corpus of new digital editions and to do such data collection at the manuscript level across the whole corpus is, for now, infeasible. We have proceeded with the process of building the database of place names in the hope that others will follow.

The VMP project harvests its place names either from a corpus of texts that have fallen into the public domain, from the paratexts of critical editions, or from editions have been digitized and processed by Optical Character Recognition (OCR) into searchable electronic text. Issues of copyright prevent us from reusing the majority of those texts openly in the way that the MoEML project has. One of the ad-

\footnotetext{
${ }^{25}$ On the forms of argument that a digital project prototype can make, see Stan Ruecker, "A Brief Taxonomy of Prototypes for the Digital Humanities," Scholarly Research and Communication 6/2 (2015): 1-11.

${ }^{26}$ Fordham Center for Medieval Studies, Exploring Place in the French of Italy, digital project, https://medievalomeka.ace.fordham.edu/exhibits/show/exploring-place.

${ }^{27}$ Janelle Jansted, “Building a Gazetteer,” 136-41; and Susan Brown, Isobel Grundy, Mariana Paredes-Olea, Jeffrey Antoniuk, and Breanna Mroczek, "Mapping Tags and Tagging Maps: Leveraging Spatial Markup for Literary History," in Cultural Mapping and the Digital Sphere: Place and Space, ed. Ruth Panofsky and Kathleen Kellett (Edmonton, 2015), 3-24.

${ }^{28}$ ENS de Lyon, Laboratoire IHRIM, BFM-Base de Français Médiéval (Lyon, 2017), http://txm.bfm -corpus.org/; Pierre Kunstmann and Achim Stein, Le Nouveau Corpus d'Amsterdam, http://www.uni -stuttgart.de/lingrom/stein/corpus.

${ }^{29}$ Ivana Djordjević, "Saracens and Other Saxons: Using, Misusing and Confusing Names in Gui de Warewic and Guy of Warwick," in The Exploitations of Medieval Romance, ed. Laura Ashe, Ivana Djordjević, and Judith Elizabeth Weiss (Cambridge, UK, 2010), 28-42.
}

Speculum 92/S1 (October 2017) 
vantages of the latter's strong relationship between spatial description and largescale editing is that it facilitates a form of innovative reading whereby it is possible to move from map to text and text to map. Øyvind Eide reminds us, however, that such shifting across media, from text to map, is riddled with a number of conceptual problems, and one medium is never quite a reflection of the other, no more than moving from speech to writing is a smooth passage, or, to use a medievalist's analogy, moving from manuscript to edited text. ${ }^{30}$

The VMP project organizes geographic information in a simple database along with other metadata about the works at hand. These include the form of the text, that is, whether it is written in prose or verse, or both; an approximate date range of composition; and an abbreviated name of the work, taken from a canonical online resource, the Dictionnaire étymologique de l'ancien français (DEAF), to ensure that data extracted from a particular edition are linked to it and have traceable editorial principles. ${ }^{31}$ The places in the database are then associated with contemporary locations, where possible, and with their corresponding geographic coordinates. Incidentally, the last step-disambiguation and association of textual data with place names and latitude-longitude pairs-is the phase of data collection and curation that is the most time-consuming and is the most often subject to debate. A text-centered approach to mapping means that the locatable places can be compared visually on a digital map interface as a way of performing a "spatial reading" of those textsalone, comparatively, or in the aggregate. In his maps of collocations of topics in large linguistic corpora and their related, collocated places, Noah Bubenhofer calls this process "visual corpus analysis" (visuelle Korpusanalyse). ${ }^{32}$

Data about texts can be compared and aggregated with those of other texts, allowing for comparative analysis and pattern discovery, and ideally can be used by researchers in tandem with close reading. The process of formalizing place names found in medieval texts, however, is characterized by a degree of uncertainty. Typical GIS functionality, such as pattern detection and statistical spatial analysis, therefore, must be used with care in our case. The VMP project to some extent exchanges precision for scale. Furthermore, not all texts in the medieval French corpus lend themselves to such analysis, since not all texts contain numerous spatial references identifiable as real geographic locations.

The VMP project attempts to take a large view of medieval French literatures after the spatial digital turn, but the gesture of curating place names is not a new one. We have place-name indices for medieval French, but they are concerned largely with the imaginary toponymies of romance and chanson de geste, and so none of them would serve as a canonical starting point for a gazetteer. ${ }^{33}$ A more useful part

\footnotetext{
${ }^{30}$ Øyvind Eide, Media Boundaries and Conceptual Modelling: Between Texts and Maps (Basingstoke, UK, 2015).

${ }^{31}$ Dictionnaire étymologique de l'ancien français (DEAF), http://www.deaf-page.de/fr/.

${ }^{32}$ Noah Bubenhofer, "Geokollokationen-Diskurse zu Orten: Visuelle Korpusanalyse," Mitteilungen des deutschen Germanistenverbandes 61/1 (2014): 45-59.

${ }^{33}$ There are three such place name indexes. Ernest Langlois, Table des noms propres de toute nature compris dans les chanson de geste imprimées (Paris, 1904); L.-F. Flutre, Table des noms propres avec toutes leurs variantes figurant dans les romans $d u$ Moyen Âge écrits en français ou en provençal et actuellement publiés ou analysés (Poitiers, 1962); André Moisan, Répertoire des nom propres de personnes et de lieux cités dans les chansons de geste françaises et les oeuvres étrangères dérivées (Geneva, 1986).
}

Speculum 92/S1 (October 2017) 
of the scholarly apparatus that favors real geographic names is a standard paratextual feature of the print critical edition, namely the index. The kinds of indices found in an edition depend on a number of factors: the nature and complexity of the textual tradition, the guidelines of a publication series, and even editorial idiosyncracy. Medievalists are familiar with glossaries of hapax legomena, textual variants, and forms of versification found in the indices of the editions they use, but also with lists of references made to other texts (called an index locorum) as well as of proper names and place names. The rationale for creating such indices seemingly lies in being able to know quickly — that is, without reading the text again-that a given work contains a reference to any such piece of information. These lists serve as an organizational infrastructure for different kinds of both textual and contextual research data designed to facilitate critical study of the edited text. The index of place names was a crucial starting point for the VMP project to begin to collect geographic information in medieval French.

For example, a scholar might be interested in which mythological figures are mentioned by Christine de Pizan in her Epistre Othea, a question quickly answered by glancing at the "Table des noms propres et des personnages anonymes" of the critical edition by Gabriella Parussa (Geneva, 1999). Likewise, historical figures mentioned in a medieval chronicle would be listed in an index nominum of a modern edition. Scholarly publishing insists on such indices because the critical edition is a social text; it is meant to communicate salient textual features to a community of researchers for the collaborative advancement of knowledge. ${ }^{34}$ When an edition's index is incomplete or is less than meticulously constructed, access to the text's information is limited. When an edition has a very complete index, a reader's ability to discover topics shared with other texts-say, the mention of a particular prince or of a castle-is more likely to occur. Whereas indices of place names have been a persistent element of the key publishing series for critical editions of medieval French texts (including the Société des Anciens Textes Français, Classiques du Moyen Âge Français, Textes Littéraires Français, and the Anglo-Norman Text Society), and they have no doubt contributed to many scholars' understanding of those texts, oddly no comprehensive monograph-length study of the geographies evoked across medieval French literature has, to my knowledge, appeared. This article's focus on place names found in texts asks some preliminary questions about how locationbased features of texts afford us new avenues for interpretation. Let us return to the example of Christine de Pizan mentioned above. Following the method suggested in this article, of extracting place names in a textual corpus and associating them with geographic coordinates, a map that uses color as a distinguishing feature of texts in a corpus might look like the visualization of the various geographies found in Christine de Pizan's oeuvre found in Fig. $1 .^{35}$

The existence of printed place-name indices was no doubt what allowed several classic studies of the image of Paris in medieval literature to be carried out. Alice Planche contrasted the historical capital's image across a corpus of Latin and French

\footnotetext{
${ }^{34}$ Unfortunately one series publishing recent editions of medieval French texts, namely Les lettres gothiques, has done away with the index.

${ }^{35}$ David Joseph Wrisley, “The Literary Geographies of Christine de Pizan," in MLA Approaches to Teaching-The Works of Christine de Pizan, ed. Andrea Tarnowski (forthcoming).
}

Speculum 92/S1 (October 2017) 


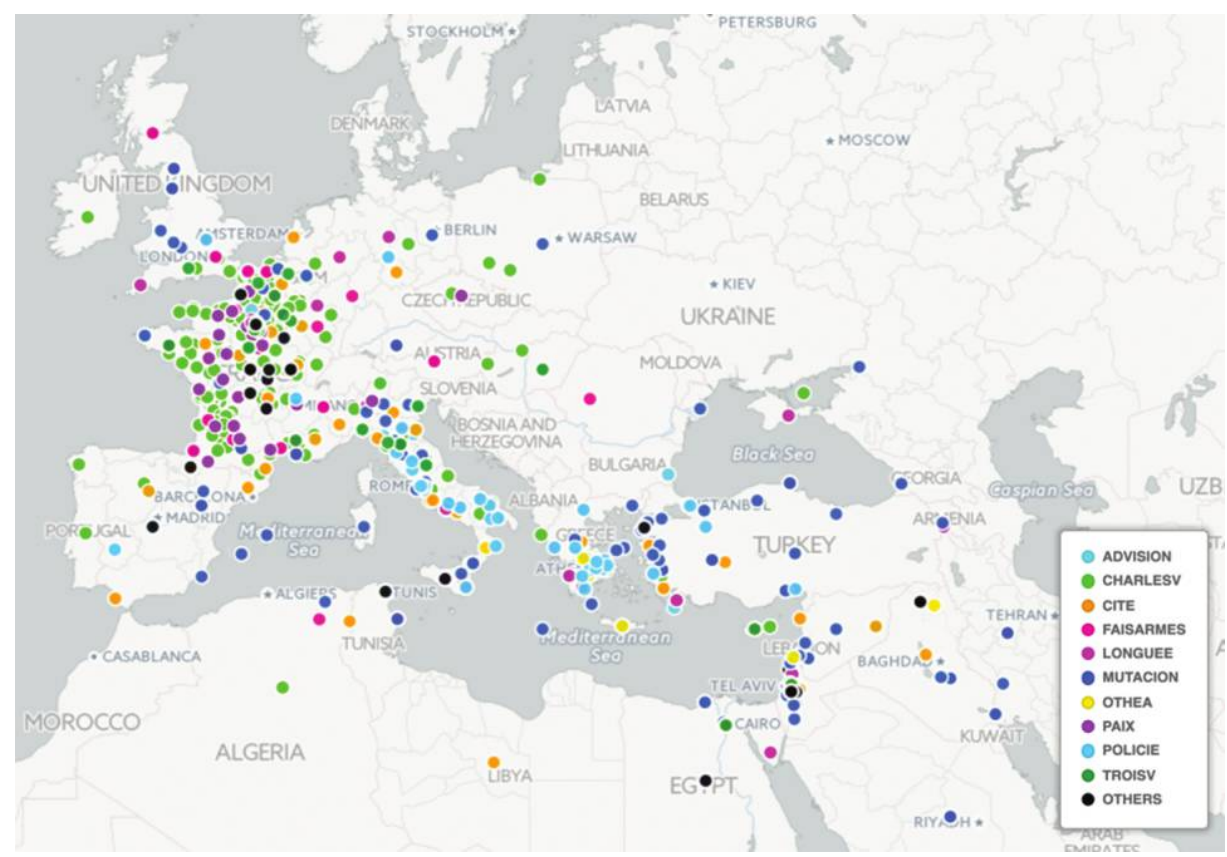

Fig. 1. A visualization of the places mentioned in the oeuvre of Christine de Pizan. An interactive version is available at http://jwrisley.com/maps/cdep and the data are available for download at https://zenodo.org/record/35350 with a CC0 1.0 license.

sources up through the mid-thirteenth century, arguing for a study of both the presence and absence of the city in key texts. ${ }^{36}$ Her approach combined geographic references to places within the city of Paris with close readings of texts, whereby the place name served as an entry point into what Matthew Wilkens has called the "literary-imaginative geography." ${ }^{37}$ Leo Olschki carried out a similar study, focusing on the representation of specific landmarks of medieval Paris, such as city walls and gates, royal residences, churches, and bridges, as well as nearby faubourgs, within the generic field of the chanson de geste. ${ }^{38}$ These studies share two features: an interest in urban geography and, more specifically, an interest in Paris, the city that has been the political center of France for many centuries. A geographical model of the medieval French corpus will have substantial data on its main city, but should not make the mistake of ignoring the many other places mentioned with high frequency as well. Texts are full of places mentioned with varying frequency, places about which we have greater or lesser amounts of information, real and imaginary places, and near and far places, in addition to geographic denominations of varying scale. Of course, the judgment of whether a place is real or imaginary can be fraught with difficulty.

\footnotetext{
${ }^{36}$ Alice Planche, "Présence et absence de Paris dans la littérature jusqu'au milieu du XIIIe siècle," in L'image de la ville dans la littérature et l'histoire médiévales (Nice, 1979), 60-69.

${ }^{37}$ Matthew Wilkens, “The Geographic Imagination of Civil War-Era American Fiction," American Literary History 25/4 (2013): 819.

${ }^{38}$ Leonardo Olschki, Paris nach den altfranzösischen nationale Epen: Topographie, Stadtgeschichte und lokale Sagen (Heidelberg, 1913).
}

Speculum 92/S1 (October 2017) 
The VMP project collects all place names that are found within the texts of its target corpus. The linked processes of disambiguation and associating geographic coordinates with place names is non-trivial. In some cases, the place names either have not been identified as a geographic location (for example, the monastery of Valberte from Adenet le Roi's Berte aus grans piés) or cannot be disambiguated by close reading. In such cases, the geographic names are included in the database, but are tagged as unidentified, leaving open the possibility of future revision. Judging a place to be "unmappable" within what we know about historical geography is a weaker claim than deciding that a place is imaginary. Interestingly, we can still speak of patterns of recurring unidentified or imaginary places. It is not the main purpose of the project, but the data are collected nonetheless.

Drawing an analogy to another field that developed in the late twentieth century, the academic field of proposography, might be useful. Proposography attempts to document people and to explore relationships among minor historical personages about whom we might know very little, but who, when studied in the aggregate, reveal patterns, or networks, that provide insight into new lines of historical inquiry. The principle of studying the relationships among parts of an interconnected system provides an important cue, we believe, for thinking about geographic references made throughout a corpus. Much early analysis in the digital humanities also focused on pattern searching in a large amount of textual data. Looking for the pattern is what Stephen Ramsay calls "the strongest point of intersection between the computational strictures of text analysis and the open ended landscape of interpretative literary studies." ${ }^{39}$ An assumption of the VMP project is that we might make the same patternbased conjectures about places. Spatial patterns in and across texts exist, and they provide a portal into the interpretative work of literary studies.

In the research done so far with the geographic information of the VMP project an emphasis has been placed on visualization. These visualizations provide a distinct view of a work's historical, political, or narrative situation. The VMP project makes the double wager that the use of geographic information can, and should, be an important part of medieval literary history; and that different ways of enriching and visualizing that data must be employed to represent the data with conceptual depth and theoretical rigor. The goal of mapping texts cannot be simply to produce a set of static maps, but rather to create a rich database of spatial information associated with literary metadata that can be combined with other interdisciplinary knowledge about the Middle Ages. Practitioners in the spatial humanities remind us that the process of mapping is "topological and relational, revealing the ties that places have with each other and tracing their embeddedness in networks that span scales and range from the local to the global." 40 As a way of thinking about texts and as the production of a visual object, both a method and an output, mapping

\footnotetext{
${ }^{39}$ Stephen Ramsay, "In Praise of Pattern," TEXT Technology: The Journal of Computer Text Processing 14/2 (2005): 177-90.

${ }^{40}$ David J. Bodenhamer, John Corrigan, and Trevor M. Harris, eds., "Introduction: Deep Maps and the Spatial Humanities," in Deep Maps and the Spatial Humanities (Bloomington, 2015), 3.
}

Speculum 92/S1 (October 2017) 
should ideally be explored in the medium, that is, dynamically. The constraints of publishing this article limit us, unfortunately, to static views. What follows in the rest of the article is a number of screen shots of visualizations generated from the project data. The process of visualizing geographical information is an iterative one based on a contextual knowledge of literary history that allows us to make targeted queries. It is also an invitation to return to close reading and to thinking more deeply about source material, or to collect more data.

The first examples here focus on mapping the locations in individual works written in medieval French. Fig. 2 is a close-up of locations mentioned in the Roman de Rou, Wace's mid-twelfth century account of the origins of the Normans, offering a clear depiction of the cross-Channel theater of their invasion, with data sparsely scattered across northern France and dense clustering around the city of Caen and in the region of Kent, which is not surprising for the subject at hand.

The visualization in Fig. 2 was created from a place-name index of the Roman de Rou using automatic geoparsing with the web service provided by Google known as Fusion Tables. ${ }^{41}$ Such automatic means of mapping a text's locations is a quick but crude way of visualizing a textual geography. The emphasis in Fig. 2 here is not on producing a clean, authoritative data set, but rather on rapid visualization for the purpose of discovery. Medievalists with some coding experience might learn how to extract toponyms and associate them with normative names and geographic coordinates using any number of online tutorials designed for humanists, thereby bypassing Google's "black box" approach. ${ }^{42}$ Alternatively, medievalists might try tools developed for such semiautomated geoparsing with modern English translations of works that interest them. ${ }^{43}$ In a semiautomatic fashion, but not without human decision making, a basic text map can be generated.

Fig. 3 illustrates the geographic information of another single text, that of Joinville's Vie de saint Louis, visualized as a heat map. According to that map style, the highest density of place names occurs where the map is orange and yellow. The question that arises immediately from the process and product of mapping is how such visuals can be interpreted. One of the elements of this particular visualization of Joinville's text worthy of remark is how it seems to turn received ideas about a text on their heads. The Vie de saint Louis chronicles Joinville's voyage accompanying Louis IX on the Seventh Crusade, and yet, while the map does feature a number of southern and eastern Mediterranean locales important for that voyage (Tunis, the Egyptian delta, and the Crusader domains, in increasing order of density), northern France is visually much more important. Out of some 290 place names found in Joinville, only some 70 are outside Europe. This is not because we have traditionally misread this text, but rather, given the number of noble families mentioned

41 "Fusion Tables," web service, available online at https://support.google.com/fusiontables/answer 12571232 .

${ }^{42}$ For example, see Fred Gibbs, "Extract and Geocode Place Names from a Text File," tutorial, http://fredgibbs.net/tutorials/extract-geocode-placenames-from-text-file.

${ }^{43}$ Randa El Khatib, Julia El Zini, Mohamad Jaber, Shady Elbassuoni, and David Joseph Wrisley, "TopoText: Interactive Digital Mapping of Literary Text," in Proceedings of COLING 2016: The 26th International Conference on Computational Linguistics; Systems Demonstrations, ed. Hideo Watanabe (Osaka, 2016), 189-93, https://aclweb.org/anthology/C/C16/C16-2040.pdf.

Speculum 92/S1 (October 2017) 


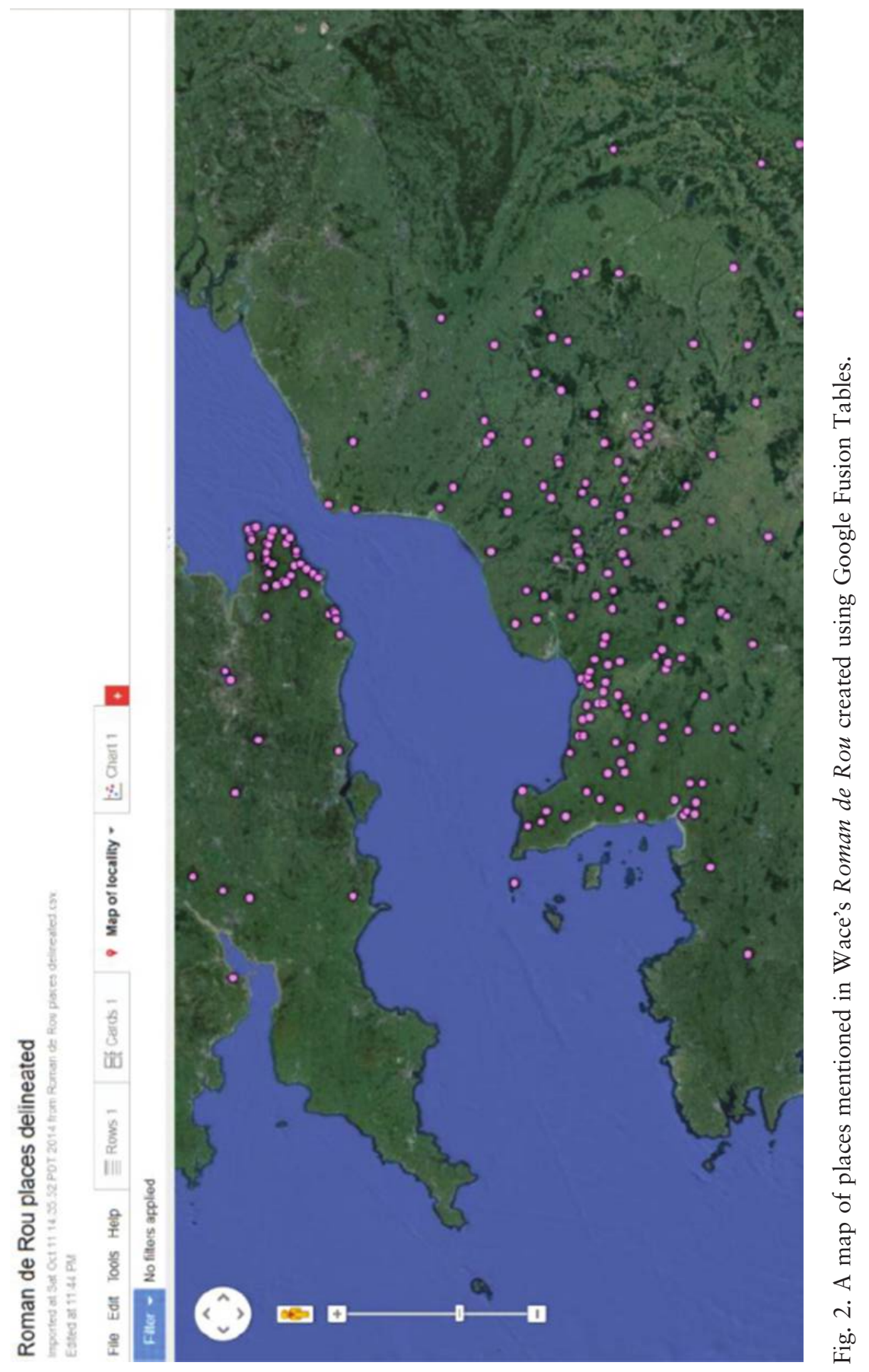

This content downloaded from 092.099.027.178 on October 01, 2018 11:09:20 AM All use subject to University of Chicago Press Terms and Conditions (http://www.journals.uchicago.edu/t-and-c). 


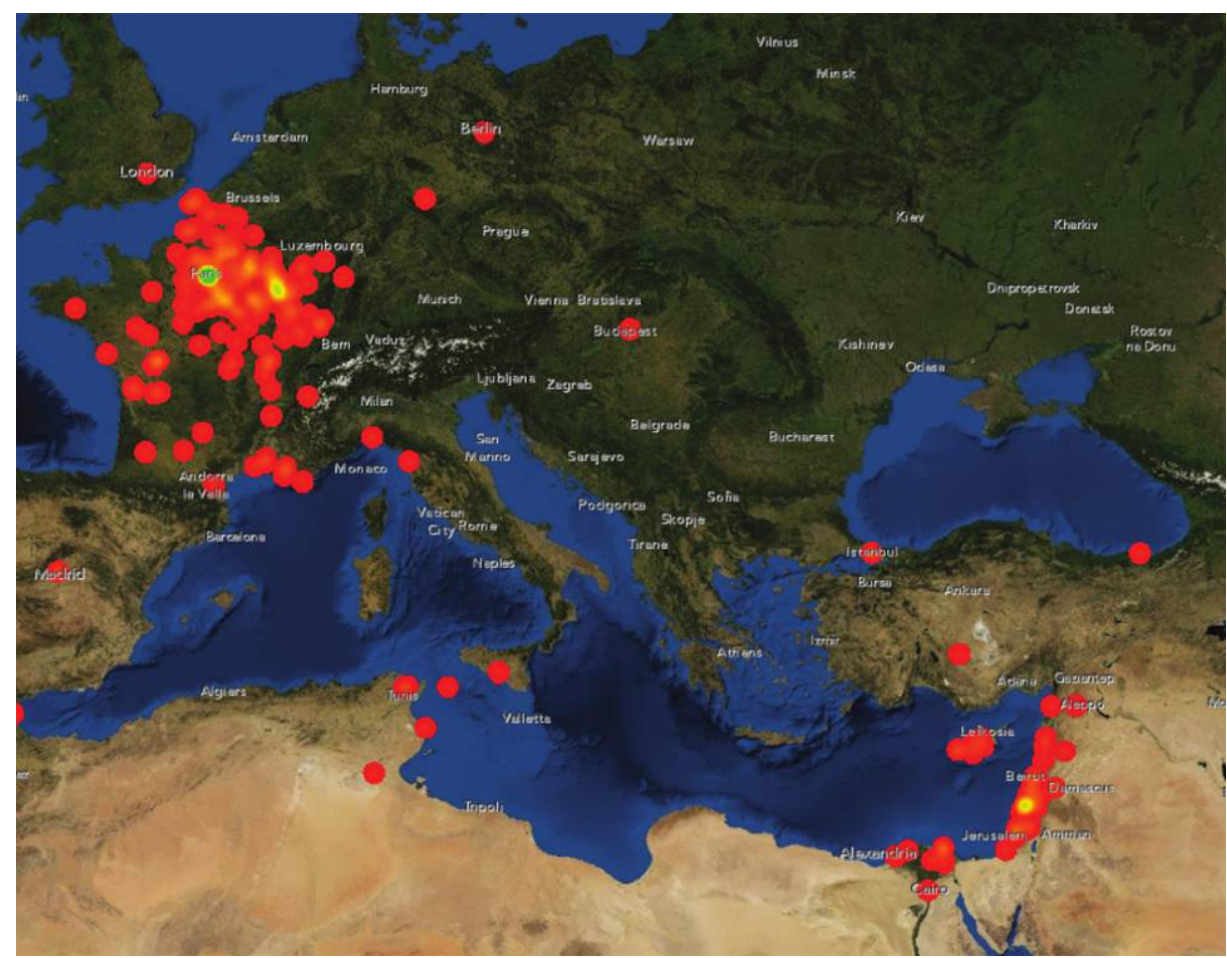

Fig. 3. A heat map of place names found in Joinville's Vie de saint Louis, created using the Geographic Information System software ArcGIS.

in Joinville's Vie de saint Louis, toponymy and onomastics are collapsed in the process of place-name extraction. Put simply, maps of the place names found in texts are not representative of the text's narrative setting alone, but also represent the narrator's sense of belonging to, and the associations he has with, geography.

Fig. 4 uses a map visualization as a way of contrasting different versions of a text, the verse Roman de la Violette, dating from the first third of the thirteenth century (in red), and its fifteenth-century rewriting in prose (in blue). Whereas the sheer numbers of place names in both verse and prose are practically the same (68 versus 65), meaningful geographic transformations have taken place in the text's rewriting. This map suggests visually how late medieval prose rewriting could involve not only the updating of language but also the localization of an older narrative within new regimes of power. It is visualized in the Google Earth interface not using the familiar Mercator projection used for web mapping, but in 3D and from the side. What is interesting about such a perspective is how it offers an alternate, if not clearer, view of those geographic transformations of the mise en prose. There are significant new clusters of blue in the regions of the Savoy, the Nivernais and the Nord. Whereas the additional places in the region of Nevers seem to align with the prose text's resituating the hero as hailing from this region, other clusters raise potential questions about the impact of fifteenth-century court cultures, the houses of Valois Burgundy and the Savoy, on the formation of the literary geographies of the time.

Speculum 92/S1 (October 2017) 


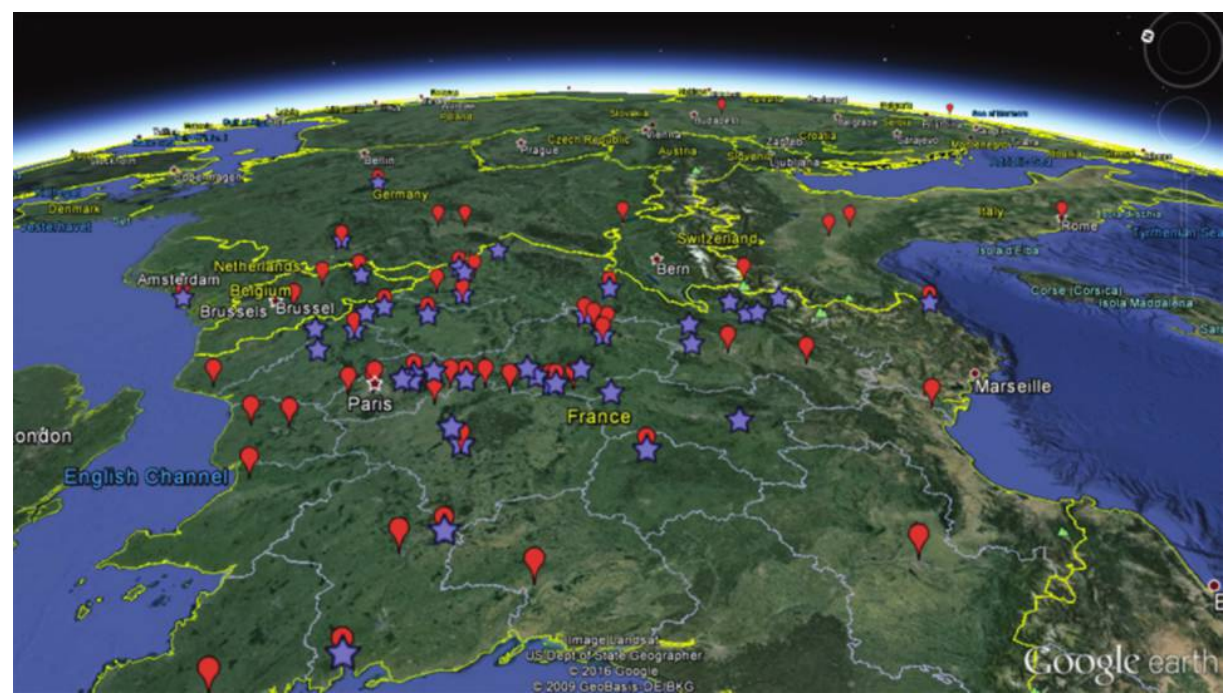

Fig. 4. A contrastive view of the place names found in the verse and prose Roman de la Violette (red and blue, respectively) visualized in Google Earth.

The digital map has emerged as an important research tool for thinking about and representing location-based humanities data. A decade has passed since Martyn Jessop outlined some of the reasons that digital humanists have been reluctant to embrace GIS. ${ }^{44}$ At present, we are witnessing a moment of intellectual effervescence, with digital mapping projects—both medieval and nonmedieval—increasingly appearing in academe. Such map visualizations are both worthwhile and challenging; they provide new lenses for seeing texts through the geographic information they contain, as well as new ways of combining, if sometimes only experimentally, different kinds of research data by means of assemblage, layering, or filtering that mapping from a geotagged data set affords us.

Figs. 2, 3, and 4 illustrate ways that the geographic scope of individual texts can be visualized, and these examples maintain a strong resemblance to forms of close reading that have dominated textual studies over the twentieth century. The second set of visualizations presented in this article looks at distant readings of geographical information from the larger corpus of medieval French. These corpus-level projects have been championed in modern literatures, where large corpora are openly available; and both the gazetteers and the computational infrastructure have facilitated such reading. Wilkens has employed computational means to extract large numbers of place names (with degrees of uncertainty that go unmentioned) that occur in the large corpora of novels written over several decades of the American Civil War. ${ }^{45}$ In addition, he is directing a project that has begun work on developing tools for the spatialization and visualization of texts contain in the HathiTrust Dig-

\footnotetext{
${ }^{44}$ Martyn Jessop, “The Inhibition of Geographical Information in Digital Humanities Scholarship,” Linguistic and Literary Computing 23/1 (2008): 39-50.

${ }^{45}$ Matthew Wilkens, "Geographic Imagination."
}

Speculum 92/S1 (October 2017) 
ital Library. ${ }^{46}$ The research objective in his work bears a resemblance to that of the VMP project: to chart patterns in the mention of place names in texts over time and space, suggesting relationships with either sociopolitical context or the investment of places in temporal slices of cultural memory. There are, however, three significant differences between the two projects. First, as we have mentioned above, open, representative, and computationally tractable corpora for the five centuries of medieval French do not yet exist. Second, the computational techniques that work well with modern English-language corpora are still underdeveloped for the linguistic particularities of medieval French, most importantly, the language's high degree of orthographic variance. Third, determining the date of composition of medieval works is not possible with precision.

This does not mean that distant readings of place for the Middle Ages are not possible. It will take time before we have the research infrastructure to carry them out, and our conclusions about change over time will remain speculative, given the uncertainty that we have about dating the composition of medieval texts. Fig. 5 illustrates the fifty most common place names found in a large corpus of medieval French texts, spanning the entire five centuries of documented textual production. The orientation along an axis from northwest Europe to the southeastern Mediterranean generally replicates the axes of textual production in medieval French. Outside France, the most common locations mentioned in texts cluster in the British Isles, the Italian peninsula, Carthage, the Greek islands, Constantinople, and the eastern Mediterranean. Whereas the predominance of those general geographic zones will not surprise scholars of medieval French, taking a closer look at other recurrent locales reveals some that are not so familiar: Blois, Pavia, Galicia, Apulia, Gascony, the Red Sea, and Cologne. More research needs to be done on these networks of places across the corpus and how they might be explained.

Fig. 6 illustrates what might be called a distant, genre-specific mapping experiment. From the geographic information extracted from all the texts categorized as chansons de geste, dates of composition were normalized to their midpoint in order to construct a choropleth map of time. Choropleth maps allow for a "color ramp" to indicate increasing numerical values, here used to represent the passage of time. The results are quite stunning, as they illustrate a slow shift in epic geographies from Old French texts on a northeast-southwest France-Iberia axis to the mirror image, Middle French texts on a northwest-southeast France-Italy-eastern Mediterranean axis. This map confirms a general claim of literary history with empirical evidence.

Whereas Figs. 5 and 6 approach the medieval spatial data of texts with no attention paid to textual provenance, the latter can also become the focal point of analysis. As mentioned above, the methodology of the VMP project has been extended to deal with a specific subcorpus of medieval French, namely Franco-Italian, in the Exploring Place in the French of Italy (EPFOI) project. Fig. 7 illustrates a detail of EPFOI data. The project site argues for the importance of a distant approach to place, especially given the corpus's composition in "a non-native language-that is French instead of Latin or a local Italian dialect." In Fig. 7, the researcher can identify a spatial "imprint" or "signature" of individual works as a way of thinking about their relation to geography. Note the specific emphasis in Martin da Canal's

${ }^{46}$ Matthew Wilkens et al., Textual Geographies, digital project, http://txtgeo.net/about.

Speculum 92/S1 (October 2017) 


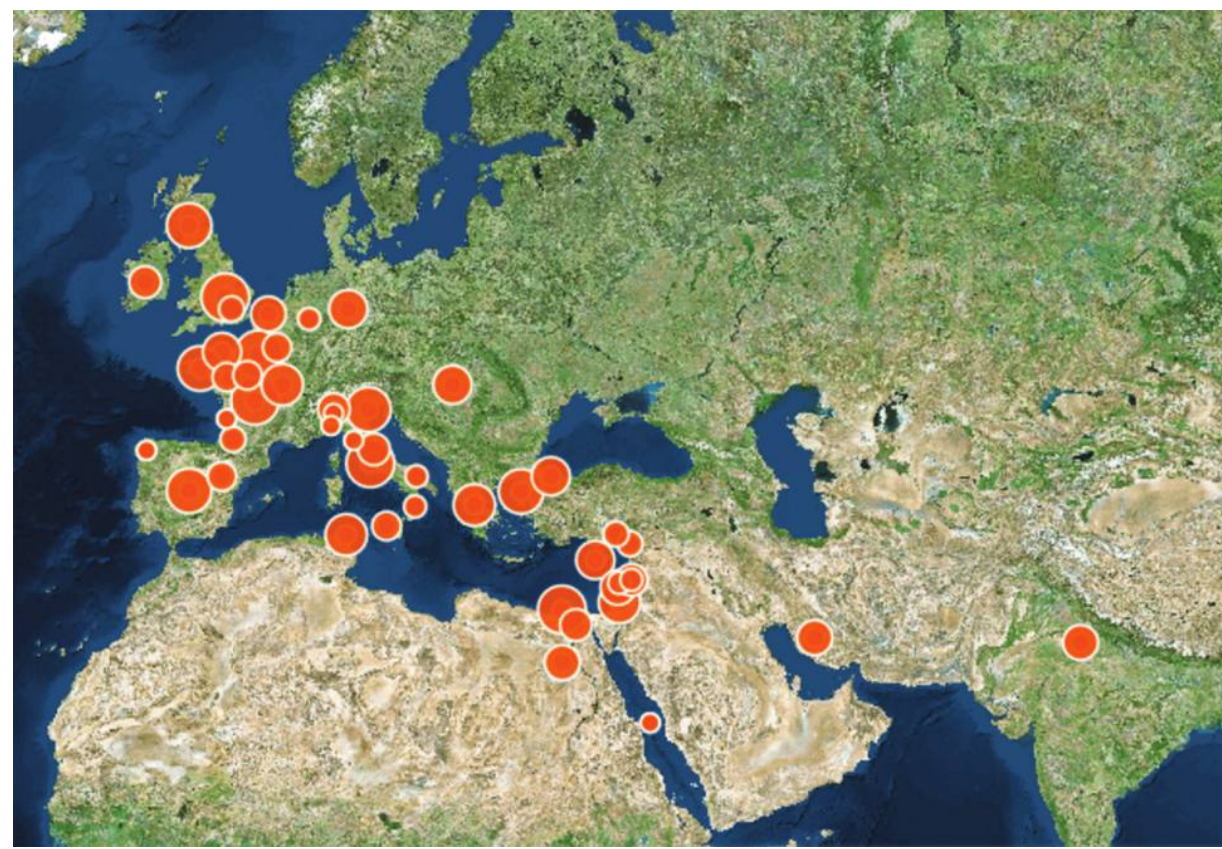

Fig. 5. The top fifty places mentioned in a corpus of $250+$ texts composed in medieval French, sized by frequency, and visualized in CARTO.

Estoire on the Veneto and the Adriatic (red), the pattern of places found in the Piemonte region of Italy in the anonymous Aquilon de Bavière (magenta), and the emphasis on the western and central regions of the Italian peninsula in Brunetto Latini's Trésor (dark green). In the composite map of the French of Italy, clusters of points in the British Isles, Asia, the empire, and the Adriatic do not occur in all texts. One can even see texts that bear witness to medieval French's status as a Mediterranean lingua franca, such as the Roman de Hector de d'Hercule, the Moamin and the Ghatrif, since these texts, although in French, do not contain a single mention of a place in France. The insights provided by the EPFOI project suggest that the work should be also carried out on texts composed and copied for the Anglo-Norman corpus. When moving to other regions, we will have to take into consideration the different generic emphases in those subcorpora.

EPFOI has productively challenged one of the aspects of the original data model of the VMP project. The former carries out its collection of spatial information at the manuscript level. Using editions of French texts based on manuscripts composed or copied in Italy, the EPFOI project found significant orthographic variance in some place names, but also widespread confusion (and perhaps purposeful exchange) of names in different manuscripts in certain genres. Modeling place at a witness level was possible, given the kinds of editions available for the Franco-Italian corpus and the awareness of cultural crossings going on in its texts documented in editions.

Perhaps the most distant visualization of the VMP project is found in the maps of the aggregate of its data. Fig. 8 represents the data with date of composition normalized to the midpoints of the accepted ranges. The benefit of this particular visuali-

Speculum 92/S1 (October 2017) 


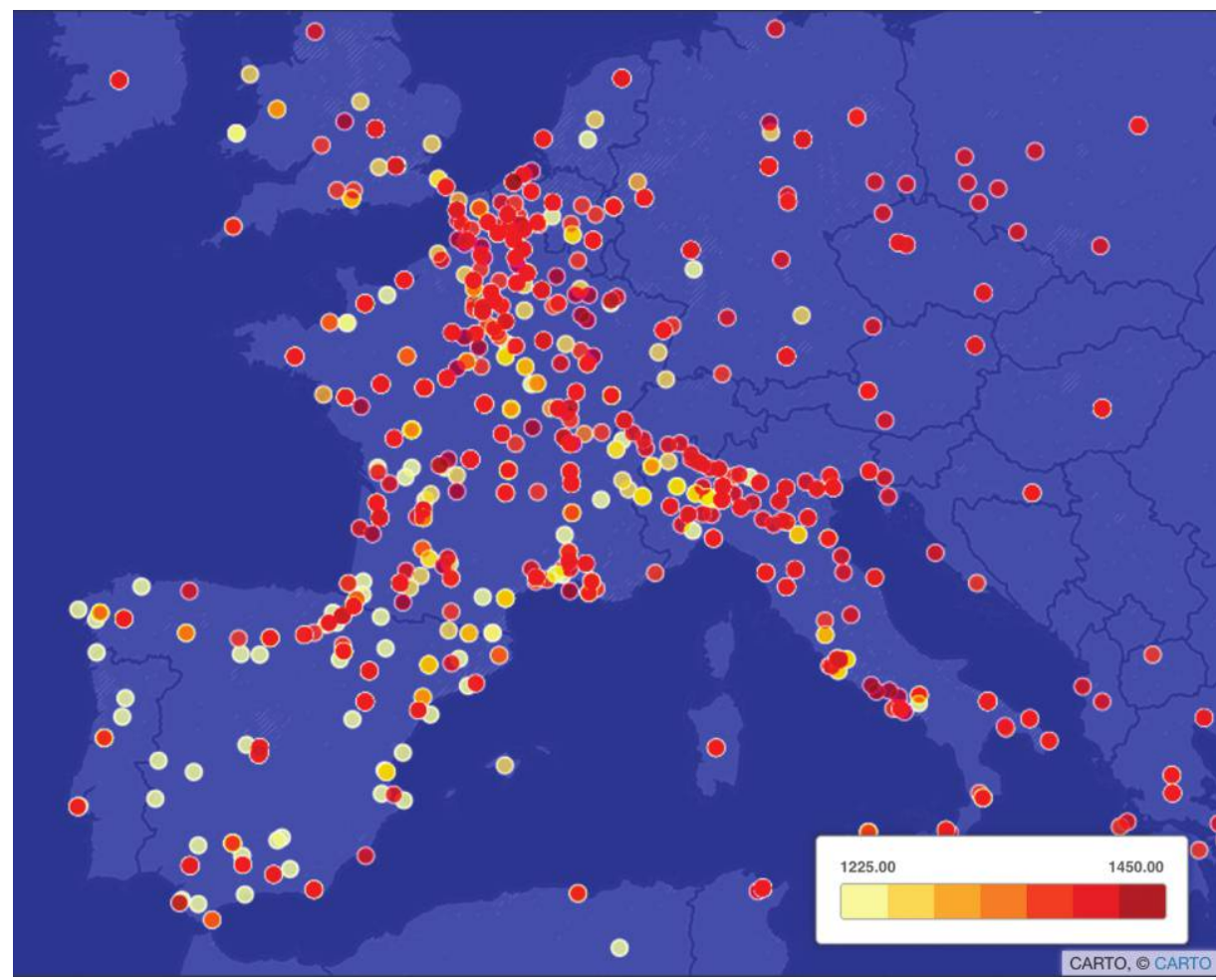

Fig. 6. The geographies found in the chansons de geste over time, visualized as a choropleth map in CARTO.

zation is the implementation of a time slider, allowing for queries about location frequencies across a user-defined time period. It provides a faceted geoview that allows the contours of named places in Europe, the Mediterranean, and the Middle East found in medieval French texts to be explored as a function of time.

One of the surprising findings of the VMP project is how infrequently, and by how few texts, Europe east of the Rhine is mentioned. Another way of exploring this finding about a map's silences has been to resort to historical data on Europe's populated areas. The aggregate of the VMP geodata extracted from texts was overlaid onto a historical map layer of major towns c. 1200 (Fig. 9). For the region east of the Rhine, generally speaking, locations mentioned in the VMP data did not correspond to areas with major towns. Data are also available for major towns for the years 800,1000 , and 1450, and similar results were observed for those periods as well. Fig. 10 is a close-up of north central Europe from the same map in Fig. 9, except that the texts mentioning the places have been labeled. We can observe how a few later medieval texts are responsible for the visible points. (Fig. 10). Not only are there very few cities that are mentioned in this contemporary corpus of medieval French, in contrast to the quite dense urbanization of medieval Lower Saxony, but also the toponyms found from imperial lands were largely regional names (Franconia, Thuringia, Bavaria, Bohemia). This observation suggests to us that not only

Speculum 92/S1 (October 2017) 


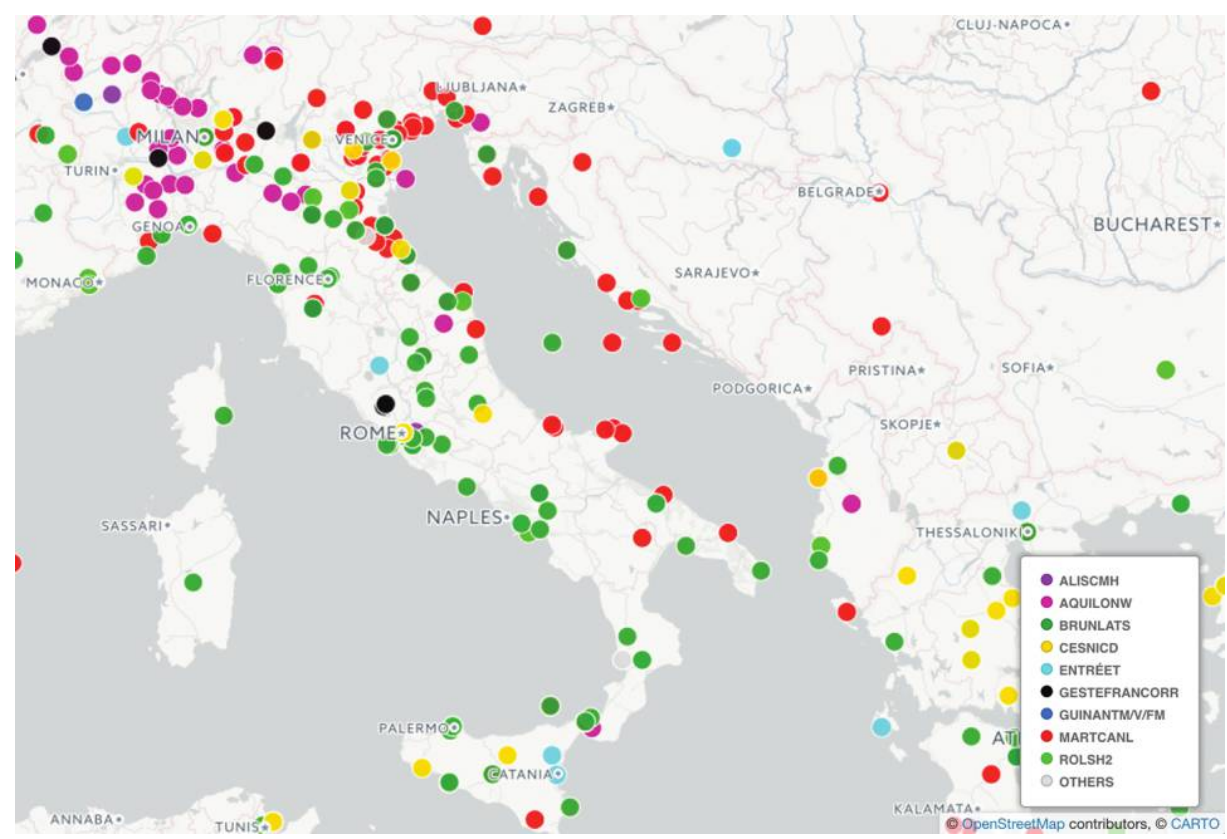

Fig. 7. A detailed view of the geographic information of nine Franco-Italian texts, colored by text, centered on the Adriatic Sea and visualized in CARTO. The composite data of the Exploring Place in the French of Italy project is available for open download at https:// medievalomeka.ace.fordham.edu/exhibits/show/exploring-place/item/450. A map gallery is available at https://medievalomeka.ace.fordham.edu/exhibits/show/exploring-place/all -maps.

should we look more deeply into the image of Germany in medieval French literature to test the hypothesis of a "borderland," but also more effort can be made to put medieval demographic and environmental data into dialogue with textual geographies. Other regions, such as the Midi of France and the Midlands of Britain, are also not mentioned. It is important to investigate a map's silences as well as its data patterns.

The third, and final, set of visualizations in this article focuses on locating medieval French vis-à-vis other vernacular and vehicular languages of the Mediterranean. The work of mapping geographical references in corpora should not be limited to French but, as we have been suggesting in this article, should extend to other co-existing languages: medieval Latin, Arabic, and Greek. Fig. 11 illustrates a comparative aggregate view of the VMP data with the spatial distribution of toponyms annotated in the Pelagios project CWP1 Latin tradition data set. Such a comparison is quite crude, since the different data sets, the states of their data, and the parameters for generating the heat map are different, but it does suggest, from a distant perspective, general contours of the geographies of medieval French texts as opposed to those of early Latin geographic treatises.

For such comparative views to be valuable and meaningful, we must assemble and interpret them carefully, since the means of data creation in one may not match the nature of another data set. In this particular case, the data from the Latin corpora come explicitly from geographic texts. It is not an equal temporal comparison, since Speculum 92/S1 (October 2017) 


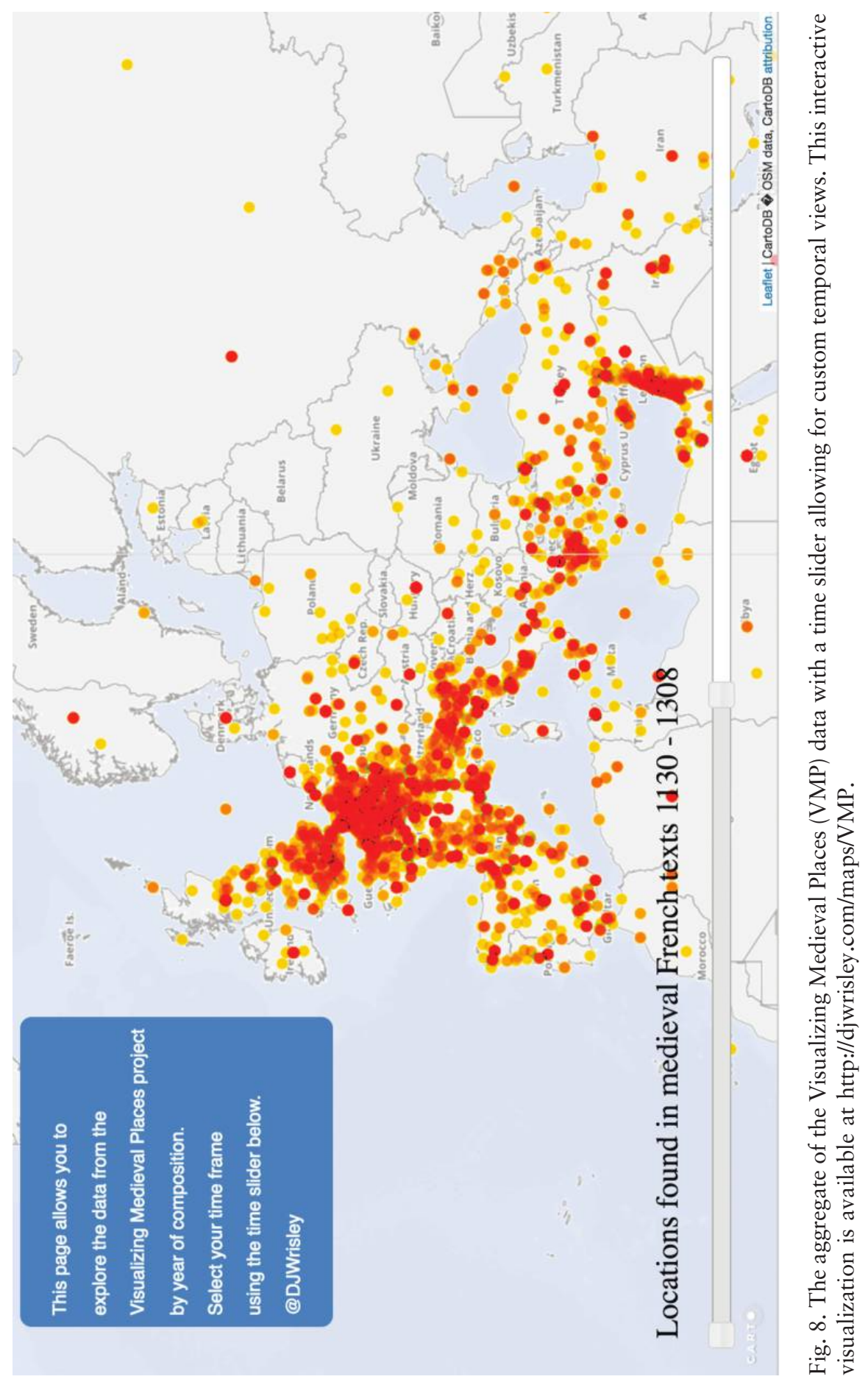

This content downloaded from 092.099.027.178 on October 01, 2018 11:09:20 AM All use subject to University of Chicago Press Terms and Conditions (http://www.journals.uchicago.edu/t-and-c). 


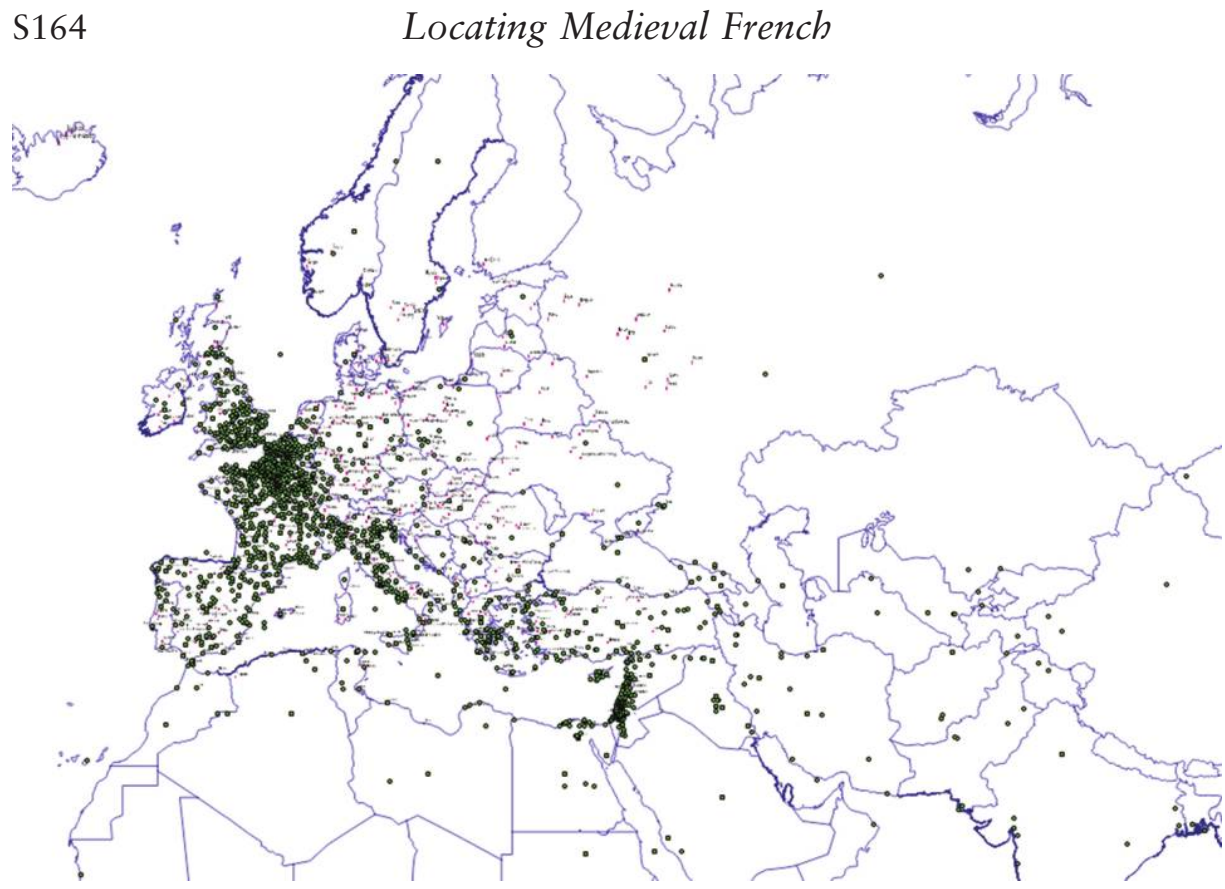

Fig. 9. VMP project data (green) overlaid on a base layer of Europe's major cities c. 1200 (pink) visualized in QGIS. The base map layer is provided via the Web Map Server of the Digital Atlas of Roman and Medieval Civilization, https://darmc.harvard.edu/data-availability.

the Latin map draws upon sources much earlier than the French. The impetus behind making such a comparative visual corpus analysis might be, however, to test the hypothesis that many place names are used in medieval French on account of those writers' knowledge of Latin geography. Much more analysis to test such a hypothesis is required than the simple views shown here. The data are coming into existence for such analyses to be attempted, but we are very much at the beginning of the enterprise. At first glance, the differences do suggest, however, the extent to which medieval French texts refer to the larger Roman Empire of late antiquity. Northern France is much better represented in the French case, along with Britain. Conspicuously absent from the French corpus is coverage of Tunisia; most parts of Greece, except Achaia; the Black Sea coastline; and Asia Minor. Such comparisons would be revealing if we were to move forward in time with the other vernaculars of Europe and medieval Latin (and in collaboration with projects such as GeoLat). ${ }^{47}$ This world of medieval data would require the social engagement of digital medievalists specializing in a wide number of disciplines and spatiotemporal concentrations, a vision of which has recently been articulated in regard to the use of linked open data about the Middle Ages. ${ }^{48}$

\footnotetext{
${ }^{47}$ Maurizio Lana, "GeoLat: Geography for Latin Literature," Institute for the Study of the Ancient World (ISAW) Papers 7/11 (2014), http://dlib.nyu.edu/awdl/isaw/isaw-papers/7/lana/.

${ }^{48}$ Ece Turnator et al., "Summary of the Proceedings of the 'Linking the Middle Ages' Workshop (May 11-12, 2015) at the University of Texas at Austin," https://repositories.lib.utexas.edu/handle $12152 / 30220$.
}

Speculum 92/S1 (October 2017) 


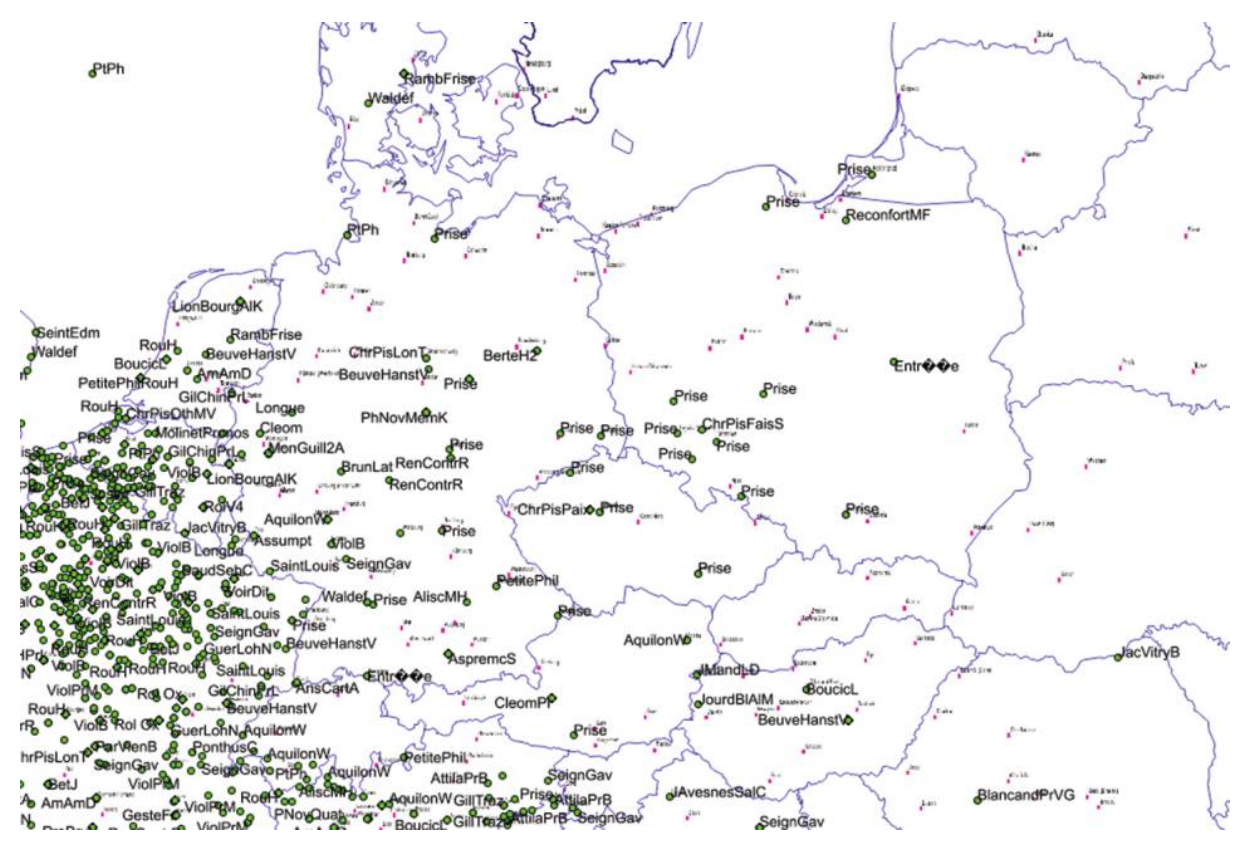

Fig. 10. A close up of the map visualization represented in Fig. 9, visualized in QGIS and with the DEAF abbreviation for texts labelled.

Fig. 12 illustrates a textual comparison akin to those found at the beginning of this article's visualizations, focused on a specific genre but differing in the fact that the corpus is constituted across European vernaculars. It illustrates three collections of Marian devotional poetry, a transnational and translinguistic phenomenon of the high Middle Ages. Represented are the place names found in the oeuvres of Gautier de Coincy and Gonzalo de Berceo as well as in the Cantigas of Alfonso X, shown in rust, lavender and green, respectively. Whereas the cases of Gautier and Gonzalo illustrate quite well how those works localize Marian devotion within relatively restricted regions, the example of Alfonso demonstrates how the textual space of the Cantigas manages to inscribe all Iberia and also make reference to many places in Western Europe. Scale in this map illustrates the contrast between the local geographies of two poets close to local communities of Benedictines and that of the man who almost became emperor. Extracting and visualizing these geographies entailed working in three vernacular languages: Castilian, Galician, and French.

Fig. 13 illustrates another way to contextualize medieval French texts within their larger Mediterranean frame. This visualization is an attempt at mapping comparative geographies of historical writing in the late medieval Mediterranean. Currently it visualizes the place names found in Guillaume de Machaut's narrative poem the Prise d'Alixandre (yellow), about the so-called crusade of Peter I of Cyprus on the city of Alexandria in 1365, along with that of the almost contemporary Mamluk chronicle recounting the same event, the Kitāb al-Ilmām (Book of Considerations) by al-Nuwairī al-Iskandarānī (green). 

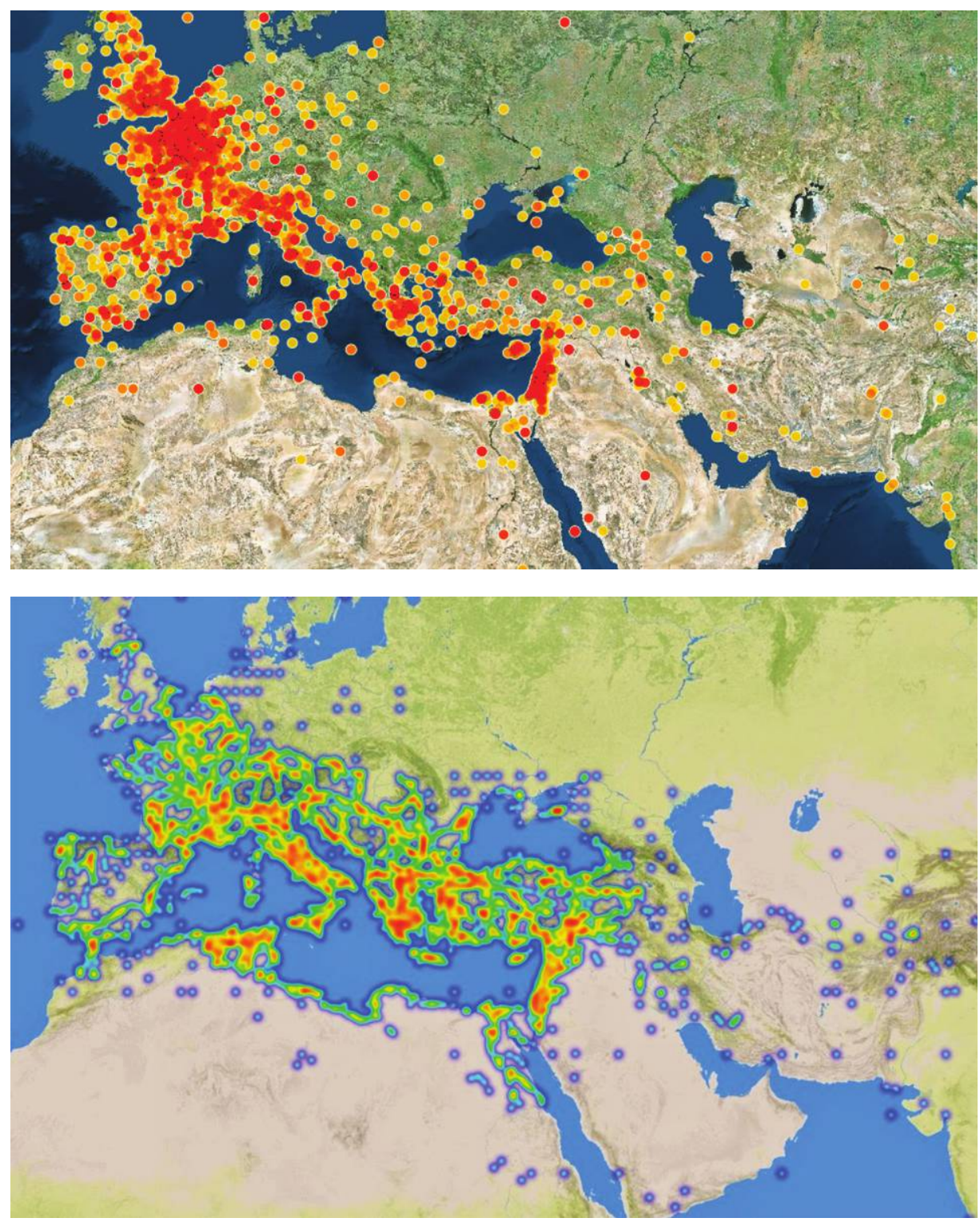

Fig. 11. A comparative heat map view of VMP data of places mentioned in medieval French texts (above) and places mentioned in the Pelagios Latin geographic tradition data (below). Pelagios data are available with a CC-BY 4.0 license : http://commons.pelagios.org/2014 106/what-have-the-romans-ever-mapped-for-us-results-from-the-latin-geographic-tradition/ and the base map is available from http://awmc.unc.edu/wordpress/tiles/ with a CC-BY 4.0 license. 


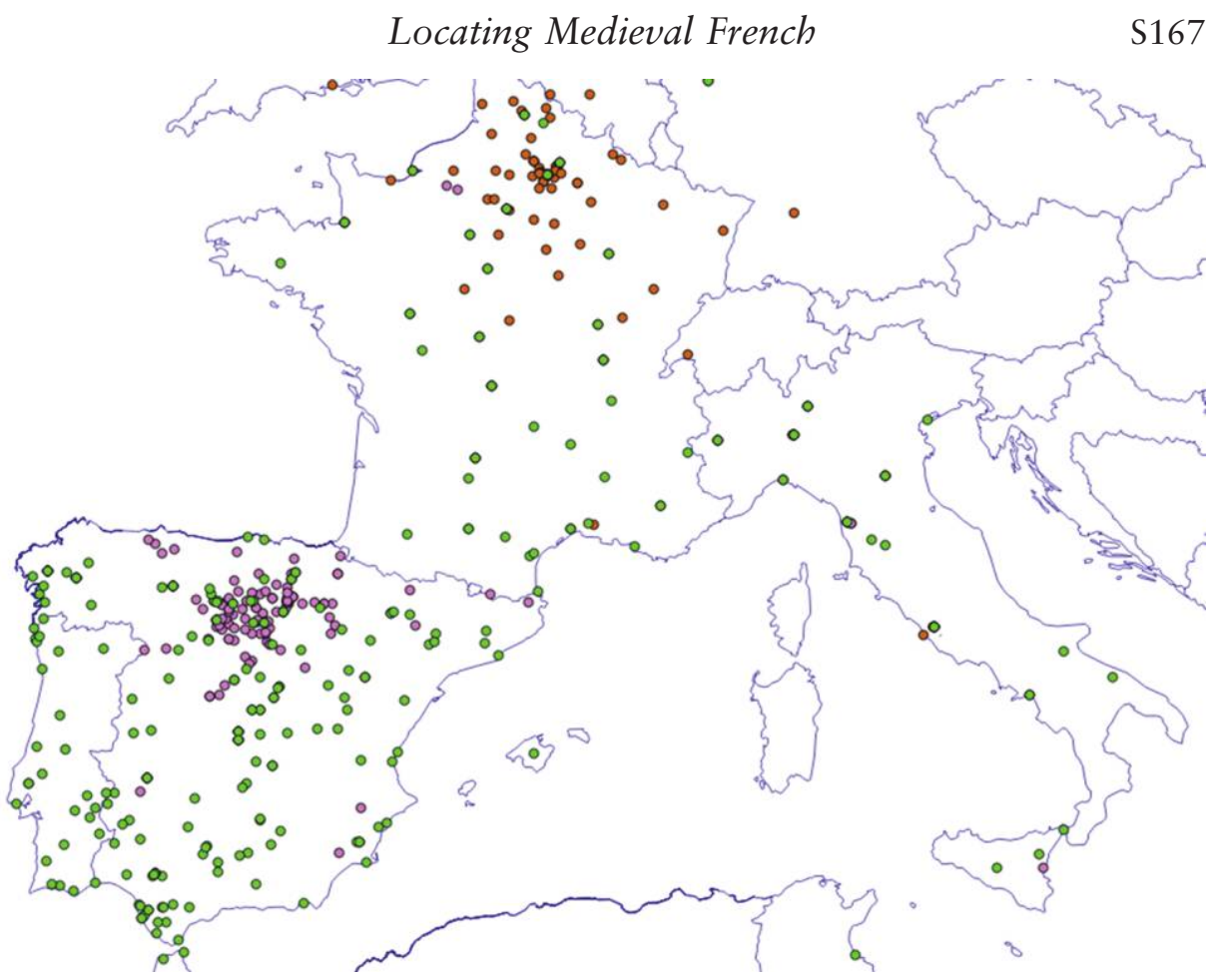

Fig. 12. A comparative visualization of geographic information taken from a corpus of Marian poetry of three authors, Gautier de Coincy (rust), Gonzalo de Berceo (lavender), and Alfonso X (green) made using QGIS.

This map is unfinished, as many projects in spatial humanities can be. At the time of the writing of this article, the data from the Kitāb al-Ilmām have not been completely georeferenced, and other texts that recount the same event have not yet been added (Philippe de Mézières' Vita sancti Petri Thomae and Leontios Machairas's Chronicle). Already visible in the map are the different civilizational spheres that are evoked by the French and the Arabic accounts, but when we look more closely, especially with the help of the DARMC map layer of Islamic cities, we also notice multiple zones of shared geography in specific "microecologies" around the Mediterranean. Such comparative views have potential in enriching Mediterranean approaches to medieval studies, given their ability to chart the notion of the named world from different nodes of textual production in Euro-Asia.

In conclusion, this article has attempted both to articulate in theory the various reasons why we map geographical information from texts and to show these in practice with examples at different scales and with diverse cultural horizons in mind. The principal objective of the visualizations contained in this article is argument-based assemblage-for hypotheses testing, pattern discovery, and investigating the chang-

Speculum 92/S1 (October 2017) 


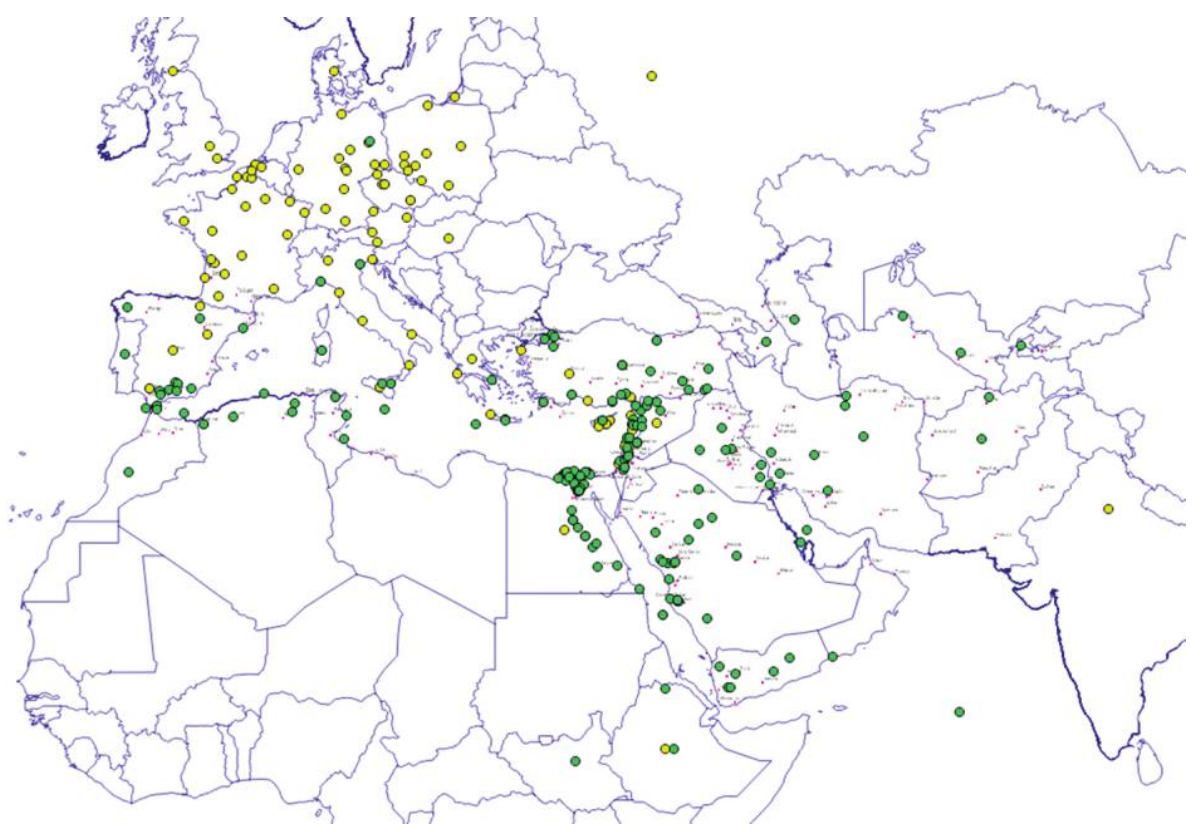

Fig. 13. A comparative visualization of geographic information taken from two sources of the Alexandrian Crusade, al-Nuwairī al-Iskandarānī's Kitāb al-Ilmām (green) and Guillaume de Machaut's Prise d'Alixandre (yellow) made using QGIS. The base map layer of major Islamic cities (pink) is provided via the Web Map Server of the Digital Atlas of Roman and Medieval Civilization https://darmc.harvard.edu/data-availability.

ing relationships across different geographic data sets. These mash-ups, like remixed music, bring together varied data sources in the same visual field to produce enriched results that go beyond the original intention of the source. This, in our opinion, is the work of spatial humanities argumentation. After the digital spatial turn, which introduced the possibility of extracting, organizing, and visualizing the geographic information present in a large number of texts of the historic cultural record, the medievalist cannot help but be humbled by the complex space-time problem that the French corpus represents. From the neogeographic representations in this article, which are based on a fraction of the geographic information that could be collected, there are numerous directions in which to expand spatial research on the period. It cannot be the research domain of one person.

Above we evoked the critical edition, suggesting how its paratext, designed for organizing extracted features of textual data, functions as a social infrastructure for academic print culture, guiding generations of readers and scholars through the intricacies of argument and textual criticism. If we did not want to stop with the printed paratext, but rather to integrate all the scribbled notes of successive scholars, and the corrections and elucidations in the books of our university libraries, we could imagine a perpetually expanding paratext. This idea is, of course, possible in digital environments, and in the case of data repositories where scholars share their data openly, with special open licenses encouraging their reuse, it has already been realized. The preliminary data of the VMP project have produced results that would

Speculum 92/S1 (October 2017) 
not have been possible without digital platforms, and yet additional research infrastructure is required to take the model of the VMP project and turn it into a social research space for cocreation and annotation. Future plans for the further-enriched VMP data include the creation of a digital gazetteer, which would open up many new avenues for further research in medieval French studies. Perhaps in subsequent phases the VMP project might be reinvented in the image of Pleiades, the communitybuilt gazetteer of the ancient world, or the Syriac Gazetteer, or might even be built, as was the al-Thurayyā Gazetteer, within the open framework of GitHub. ${ }^{49}$ This work would extend the project beyond collecting and visualizing to sharing that geographic information. Classicists and now Middle Eastern scholars have led the way in humanities spatial infrastructure research and in the creation of open text bases. The creative and innovative scholarship in their fields can hopefully inspire Western and Mediterranean medievalists to do the same, taking into account the particularities of our multilingual medieval past.

\footnotetext{
${ }^{49}$ These three gazetteers can be found at https://pleiades.stoa.org/, http://syriaca.org/geo/index.html, and https://althurayya.github.io/, respectively.
}

David Joseph Wrisley, New York University Abu Dhabi (djw12@nyu.edu)

Speculum 92/S1 (October 2017) 